\title{
Amino Acid Transporters as Potential Therapeutic Targets in Thyroid Cancer
}

\author{
Keisuke Enomoto, Muneki Hotomi \\ Department of Otolaryngology-Head and Neck Surgery, Wakayama Medical University, Wakayama, Japan
}

Thyroid cancer cells have a high amino acid demand for proliferation, invasion, and metastasis. Amino acids are taken up by thyroid cancer cells, both thyroid follicular cell and thyroid parafollicular cells (commonly called "C-cells"), via amino acid transporters. Amino acid transporters up-regulate in many cancers, and their expression level associate with clinical aggressiveness and prognosis. This is the review to discuss the therapeutic potential of amino acid transporters and as molecular targets in thyroid cancer.

Keywords: Thyroid neoplasms; Large neutral amino acid-transporter 1; Amino acid transport systems; 2-amino-3-(4-((5-amino2-phenylbenzo(d)oxazol-7-yl)methoxy)-3,5-dichlorophenyl)propanoic acid; Boron neutron capture therapy; Proto-oncogene proteins c-myc

\section{INTRODUCTION}

Amino acids play essential roles in protein synthesis, which promotes cell growth and proliferation in both normal cells and cancer cells [1-4]. Nonessential amino acids are synthesized from essential amino acids; however, essential amino acids cannot be synthesized de novo. Amino acids, particularly essential amino acids, are required to be taken up by various cells via different amino acid transporters. Among the 20 standard amino acids, 11 are nonessential: alanine, asparagine, aspartate, cysteine, glutamate, glutamine, glycine, proline, serine, tyrosine, and arginine; the remaining nine are essential: histidine, isoleucine, leucine, lysine, methionine, phenylalanine, threonine, tryptophan, and valine.

Thyroid cancer (TC) is the most frequent endocrine carcinoma, with an incidence of 12.9, 25.8, and 64.1 per 100,000 individuals in the USA (2011 to 2015), Puerto Rico (2011 to 2015), and Korea (2008 to 2010), respectively [5,6]. Most TCs are as-

Received: 8 May 2020, Revised: 6 June 2020, Accepted: 9 June 2020

Corresponding author: Muneki Hotomi

Department of Otolaryngology-Head and Neck Surgery, School of Medicine, Wakayama Medical University, 811-1 Kimiidera, Wakayama 641-8509, Japan Tel: +81-73-441-0651, Fax: +81-73-446-3846

E-mail: mhotomi@wakayama-med.ac.jp sociated with a low mortality risk, with gradual progression, no clinical metastasis, and an excellent prognosis [7]. Some papillary thyroid carcinomas (PTCs) such as microcarcinoma with very low mortality risk may not require surgical treatment (clinical active surveillance) [8-10]. However, several PTCs associated with a high mortality risk require treatment including surgery, ${ }^{131} \mathrm{I}$-radiotherapy, and chemotherapy targeting the vascular endothelial growth factor receptor. In particular, anaplastic thyroid cancer (ATC) is associated with a high mortality risk, with a 3-year survival ratio of $<20 \%[11,12]$. This review focuses on amino acid transporters as molecular therapeutic targets and their clinical applications for TC.

\section{AMINO ACID TRANSPORTERS AND THYROID CANCER}

Transporters are classified into two broad categories based on adenosine triphosphate (ATP) dependence [13]. ATP-dependent

Copyright $\odot 2020$ Korean Endocrine Society

This is an Open Access article distributed under the terms of the Creative Commons Attribution Non-Commercial License (https://creativecommons.org/ licenses/by-nc/4.0/) which permits unrestricted non-commercial use, distribution, and reproduction in any medium, provided the original work is properly cited. 
transporters, known as ATP-binding cassette (ABC) transporters, hydrolyze ATP to obtain energy for transmembrane translocation of their substrates. Transporters without an ATPase domain, called solute carriers (SLCs), facilitate diffusive transport. Most amino acid transporters are SLCs, and belong to several groups based on their substrates and sodium dependency; however, they have been classified in accordance with their sequence homology. L-type amino acid transporters (LATs) are categorized as system L transporters, which transport neutral amino acids including alanine, asparagine, cysteine, glutamine, glycine, proline, serine, tyrosine, isoleucine, leucine, methionine, phenylalanine, threonine, and valine.

Among amino acid transporters, L-type amino acid transporter 1 (LAT1; SLC7A5), LAT2 (SLC7A8), LAT3 (SLC43A1), LAT4 (SLC43A2), alanine-serine-cysteine transporter (ASCT, $S L C 1 A 5)$, amino acid transporter $\mathrm{B}(0,+)\left(\mathrm{ATB}^{0+}, S L C 6 A 14\right)$, cystine/glutamate exchanger (xCT, $S L C 7 A 11)$, and cationic amino acid transporter 3 (CTR3, SLC7A3) are associated with various cancers (Table 1). LAT1 and LAT2 are the first and sec- ond system $\mathrm{L}$ amino acid transporter isoforms, discovered in 1998 [14,15] and 1999 [16-18], respectively. In healthy individuals, LAT1 is expressed in the Sertoli cells, kidney distal tubules, pancreatic islet cells, and gastrointestinal organs including the esophagus, stomach, small intestine, and colon [19]. LAT1 is demonstrated strong upregulation in many cancers, and higher upregulation of LAT1 associate with poor survival in various cancers including head and neck squamous cell carcinoma (HNSCC), breast, lung, esophagus, and biliary duct cancers [20]. Furthermore, LAT1 suppression decreases cell growth and proliferation through attenuation of mammalian target of rapamycin (mTOR) signaling in many cancer cells [20,21], and impaired migration and invasion of gastric and prostate cancer cells $[22,23]$. Thus, LAT1 is a strong candidate for moleculartargeted therapy for various cancers. Furthermore, TC cells reportedly display LAT1 upregulation, thus rendering LAT1 a novel molecular therapeutic target [24-27].

LAT2 has similar expression patterns as LAT1, being primarily expressed in gastrointestinal organs and the kidney proximal

Table 1. Amino Acid Transporters Associated with Thyroid Cancer

\begin{tabular}{|c|c|c|c|c|c|}
\hline Protein & Gene & Major substrates & Co-activator & Expression in thyroid cancer & $\begin{array}{c}\text { Outcome on } \\
\text { overexpression }\end{array}$ \\
\hline LAT1 & SLC7A5 & Leu, Ile, Val, Phe, Met, His, Tyr, Trp & 4F2hc/CD98 & $\begin{array}{l}\text { Upregulation in } \\
\text { PTC }[24] \\
\text { ATC }[24,26] \\
\text { MTC }[27]\end{array}$ & $\begin{array}{l}\text { Poor in } \\
\text { PTC }[24,25] \\
\text { ATC }[26]\end{array}$ \\
\hline LAT2 & SLC7A8 & $\begin{array}{l}\text { Ala, Asn, Cys, Gln, Gly, Ile, Leu, Met, Phe, Ser, } \\
\text { Thr, Tyr, Val }\end{array}$ & 4F2hc/CD98 & $\begin{array}{l}\text { Upregulation } \\
\text { PTC [30], MTC [27] } \\
\text { No change in } \\
\text { FTC, ATC [30] }\end{array}$ & No data \\
\hline LAT3 & SLC43A1 & Leu, Ile, Val, Phe, Met & No & No data & No data \\
\hline LAT4 & $S L C 43 A 2$ & Leu, Ile, Val, Phe, Met & No & $\begin{array}{l}\text { Downregulation in } \\
\text { PTC, FTC, PDTC, ATC [30] }\end{array}$ & No data \\
\hline ASCT2 & $S L C 1 A 5$ & Ala, Ser, Cys, Thr, Gln, Asn, Glu & No & $\begin{array}{l}\text { Upregulation in } \\
\text { MTC [39] } \\
\text { Nochange in } \\
\text { PTC, FTC, PDTC, ATC [39] }\end{array}$ & $\begin{array}{l}\text { No change in } \\
\text { all }^{\mathrm{a}}[39]\end{array}$ \\
\hline $\mathrm{ATB}^{0+}$ & SLC6A14 & Ala, Ser, Cys, His, Met, Ile, Leu, Val, Phe, Tyr, Trp & No & No data & No data \\
\hline $\mathrm{xCT}$ & SLC7A11 & Gln & 4F2hc/CD98 & No data & $\begin{array}{l}\text { Poor in } \\
\text { PTC [25] }\end{array}$ \\
\hline CTR3 & SLC7A3 & Arg, Lys & No & No data & $\begin{array}{l}\text { Poor in } \\
\text { PTC [25] }\end{array}$ \\
\hline
\end{tabular}

LAT1, L-type amino acid transporter 1; His, histidine; Met, methionine; Leu, leucine; Ile, isoleucine, Val, valine; Phe, phenylalanine; Ala, alanine; Asn, asparagine; Cys, cysteine; Gln, glutamine; Gly glycine; Ser, serine; Thr, threonine; Trp, tryptophan; Tyr, tyrosine; Arg, arginine; Lys, lysine; PTC, papillary thyroid cancer; ATC, anaplastic thyroid cancer; ASCT, alanine-serine-cysteine transporter; MTC, medullary thyroid cancer; FTC, follicular thyroid cancer; PDTC, poorly differentiated thyroid cancer; ATB, amino acid transporter B; xCT, cystine/glutamate exchanger; CTR, cationic amino acid transporter.

${ }^{\text {aTT }}$ The survival was calculated in thyroid cancer, in the following subtypes: PTC, FTC, MTC, PDTC, and ATC. 
tubule [19]. LAT2-knockout mice display a mild phenotype and almost no visible symptoms except for aminoaciduria [28]. Both LAT1 and LAT2 contain 12 transmembrane domains that form a channel for their substrates [29]. However, it remains unclear whether LAT2 expression levels vary during TC. Badziong et al. [30] reported that LAT2 is upregulated in PTC but its levels remain unchanged in follicular thyroid cancer (FTC) and ATC. However, Barollo et al. [27] reported LAT2 downregulation in medullary thyroid cancer (MTC), a neuroendocrine tumor. Thus far, data on LAT2 expression in TC are controversial.

LAT3 has been isolated through expression cloning from hepatocarcinoma cells [31] and its primary structure is reportedly identical to that of prostate cancer over-expressed gene 1(POV1), which is reportedly upregulated in prostate cancer [32]. The substrate selectivity of LAT3 is similar to that of LAT1; its substrates include isoleucine, leucine, methionine, phenylalanine, and valine (Table 1) [31]. LAT3 is upregulated in the liver, skeletal muscle, and pancreas [31] and apparently serves as a critical transporter in several cancers. LAT3 knockdown significantly inhibits the leucine uptake, cell proliferation, and metastasis in human prostate cancer cell lines in vitro [33]. LAT3 is potentially associated with cancer cell proliferation and metastasis; however, no study has reported the expression of LAT3 in TC.

LAT4 was identified on the basis of its sequence homology with LAT3 [34]. LAT4 is upregulated in peripheral blood, the placenta, kidney, and spleen [34]. Badziong et al. [30] reported that LAT4 is downregulated in PTC, FTC, and ATC. In contrast, LAT4 is overexpressed in Graves' disease. However, the role of LAT4 in thyroid carcinogenesis remains unclear.

ASCT2, an $\mathrm{Na}^{+}$-dependent neutral amino acid transporter encoded by SLC1A5, is predominantly localized at the cell membrane [35] and mediates the exchange of amino acid substrates, particularly mediating rapid glutamine uptake in proliferating cancer cells [36]. ASCT2 upregulation worsens the prognosis of HNSCC, clear-cell renal-cell carcinoma, gastric cancer, triplenegative breast cancer, ovarian cancer, and other cancers [37,38]. Kim et al. [39] (2016) reported ASCT2 upregulation in MTC originating from parafollicular cells but not in other TCs of follicular origin, including PTC, FTC, poorly differentiated carcinoma, and ATC.

$\mathrm{ATB}^{0+}$ is a member of the $\mathrm{Na}^{+}$- and $\mathrm{Cl}^{-}$-dependent neurotransmitter transporter family, and is upregulated in the lungs, fetal lungs, trachea, and salivary gland. $\mathrm{ATB}^{0+}$ transports both neutral and cationic amino acids, and has approximately $60 \%$ amino acid similarity with glycine transporters GLYT1 and GLYT2
[40]. The blockade of $\mathrm{ATB}^{0+}$ is associated with a reduction in pancreatic cancer cell proliferation, indicating the potential of $\mathrm{ATB}^{0+}$ as a drug target in cancer chemotherapy [41]. However, the role of $\mathrm{ATB}^{0+}$ in $\mathrm{TC}$ remains unclear.

$\mathrm{xCT}$ is a cysteine/glutamate transporter, which plays a key role in glutathione synthesis. $\mathrm{xCT}$ overexpression decreases endogenous reactive oxygen species (ROS) levels and increases the migration and invasion of glioblastoma cells [42]. Furthermore, $\mathrm{xCT}$ accelerates tumor growth and tumor associated-seizures and helps predict the outcomes of patients with malignant glioma [43]. In PTC, xCT upregulation was reportedly associated with poor survival [25].

CTR3 is a sodium-independent cationic amino acid transporter, which is glycosylated and localized at the plasma membrane [44]. Shen et al. [25] reported that $S L C 7 A 3$ expression is associated with extrathyroidal extension, higher cancer stage, BRAF, RAS mutation, and mortality in PTC.

Though the protein expression of amino acid transporters alters in many cancers including TC, gene mutations of amino acid transporters are still unclear. The point mutations in $S L$ C7A5 were reported just one case with a missense mutation in breast cancer [45]. Bik-Multanowski and Pietrzyk [46] screened for SLC7A5 mutations in phenylketonuric patients and three polymorphism and one new mutation (G41D) were detected [47]. Recently, SLC7A8 expression was showed in the mouse inner ear and that abolish of LAT2 resulted in age-related hearing loss [48]. They also reported significant decreases in LAT2 transport activity for patient's variants (p.V302I, p.R418H, p.T402M, and p.V460E) in SLC7A8. Gene mutations of amino acid transporters according to TC has not been clarified at the moment.

\section{LAT1 AND THYROID CANCER}

LAT1 is one of the most appropriate candidates for moleculartargeted therapy for TC from follicular cell (Table 2). Shen et al. [25] reported that a poor prognosis is associated with SLC7A5 upregulation in PTC. Hafliger et al. [24] and Enomoto et al. [26] reported the therapeutic potential of the selective LAT1 inhibitor JPH203 in TC. Hafliger et al. [24] reported that LAT1 is overexpressed in PTC and ATC, and LAT1 overexpression is associated with a poor prognosis of PTC [24]. Enomoto et al. [26] reported that LAT1 and co-expressed 4F2hc are overexpressed in ATC patients through immunohistochemical analyses, and LAT1 overexpression is associated with poor outcomes in ATC. Both studies confirmed that JPH203 inhibits the prolif- 
Table 2. Studies Reporting the Role of LAT1 in Thyroid Cancer

\begin{tabular}{|c|c|c|c|c|}
\hline & Hafliger et al. [24] & Enomoto et al. [26] & Barollo et al. [27] & Shen et al. [25] \\
\hline Histology & PTC, ATC & ATC & MTC & PTC \\
\hline Clinical sample analysis & mRNA & $\mathrm{IHC}$ & mRNA, IHC & mRNA \\
\hline Survival analysis & PTC & ATC & & \\
\hline \multicolumn{5}{|l|}{ In vitro study } \\
\hline Inhibitors & JPH203 & & JPH203, siRNA & \\
\hline Cell cycle analysis & & G0/G1 cell cycle arrest & & \\
\hline Apoptosis analysis & TUNEL positive & & & \\
\hline In vivo mouse study & Conditional KO & xenograft model & & \\
\hline
\end{tabular}

eration of human TC cell lines in vitro. Furthermore, Hafliger et al. [24] and Enomoto et al. [26] reported the antitumor effect of JPH203 in different in vivo models, e.g., v-raf murine sarcoma viral oncogene homolog $\mathrm{B} 1$ (BRAF) $^{\mathrm{V} 600 \mathrm{E}} / 4,5$-bisphosphate 3-kinase catalytic subunit alpha (PIK3CA $)^{\mathrm{H} 1047 \mathrm{R}}$-double mutant mice that constitute spontaneous ATC models with an activated mitogen-activated protein kinase (MAPK) and phosphatidylinositol 3-kinase (PI3K) pathway, and a xenograft mouse model established using ATC cell line 8505C containing BRAF, PI3K3R1/2, and p53 mutations [48,49]. JPH203 can thus be considered a highly reliable therapeutic candidate for TC, particularly ATC.

Furthermore, LAT1 may be considered a therapeutic target in MTC, which originates from parafollicular cells. Barollo et al. [27] confirmed that LAT1 overexpression in MTC paralleled glucose transporter 1 overexpression and that LAT1 is overexpressed in an MTC cell line, TT, through Western blotting. However, it remains unclear whether inhibiting overexpressed LAT1 attenuates MTC proliferation.

In numerous cancers, LAT1 upregulation is associated with metastasis. In non-small-cell lung cancers, lymph node metastasis-positive squamous cell carcinomas express LAT1, while no positive LAT1 signals have been reported in non-metastatic cells [50]. A group of cells with LAT1 upregulation displayed larger metastatic lesions in gastric carcinoma [51]. LAT1 expression in neuroendocrine tumors was significantly associated with lymph node metastasis [52]. The functional significance of LAT1 in metastasis has been reported. RNAi-mediated LAT1 knockdown inhibited the migration and invasion of gastric cancer cells [23] and a cholangiocarcinoma cell line [53]. 2-Aminobicyclo-(2,2,1)-heptane-2-carboxylic acid (BCH) reportedly inhibited proliferation and migration in a human epithelial ovar- ian cancer cell line [54]. Although the positive association between cancer metastasis and LAT1 expression has been reported, no studies have indicated the association between LAT1 overexpression and TC metastasis thus far.

\section{CLINICAL APPLICATION OF LAT1- TARGETING AGENTS}

\section{LAT1 inhibitors}

$\mathrm{BCH}$ is a prototypical non-selective LAT1 inhibitor [55]. BCH inhibits LAT1, thus inhibiting the uptake of L-leucine with an IC50 of 73.1 to $78.8 \mu \mathrm{M}$ in three cancer cell lines (human oral epidermoid carcinoma, human osteogenic sarcoma, and rat glioma cells) [56]. Because high $\mathrm{BCH}$ concentrations are required for inhibiting highly proliferous cancer cells, no clinical trials have been performed thus far. JPH203 (KYT-0353) is a selective LAT1 inhibitor with an IC50 of $0.06 \mu \mathrm{M}$ for L-leucine [57], strongly inhibiting HT-29 colon cancer cell growth, with an IC50 value of $4.1 \mu \mathrm{M}$. In 2017, Kongpracha et al. [58] synthesized another LAT1 inhibitor, SKN103, based on the structure of T3 and reported the inhibition of L-leucine uptake of 4 human cell lines (pancreas ductal adenocarcinoma, squamous cell carcinoma, cervix adenocarcinoma, and adenocarcinomic alveolar basal epithelia) and inhibition of tumor cell growth in two cell lines (pancreas ductal adenocarcinoma, and squamous cell carcinoma); however, no in vivo assays have been conducted thus far.

JPH203 was recently evaluated in a first-in-human phase 1 clinical trial (UMIN Clinical Trials Registry UMIN000016546). Okano et al. [59] reported among 17 patients with advanced solid tumors, one patient with biliary tract cancer presented a partial response and five patients with biliary tract cancer or 
colorectal cancer presented stable disease. Common treatmentrelated adverse events included malaise, nausea, and a grade 1 or 2 fever. JPH203 is currently being evaluated in a phase 2 clinical trial among patients with advanced biliary tract cancers (UMIN Clinical Trials Registry UMIN000034080). To our knowledge, no LAT1 inhibitor has been clinically assessed for $\mathrm{TC}$, in both follicular cell and parafollicular cells thus far.

\section{Diagnosis via positron emission tomography}

Imaging analysis of TC has largely been dependent on radioactive iodine such as ${ }^{123} \mathrm{I}$ and ${ }^{131} \mathrm{I}$ scintigraphy. Positron emission tomography (PET) has greater sensitivity than single-photon imaging (planar and single photon emission computed tomography [SPECT]) [60]. Upon uptake of radioactive iodine into follicular cells via the sodium/iodide symporter, positron-labeled ${ }^{124}$ I was developed as a PET tracer to detect TC. These primarily help detect metastatic and recurrent foci of TC after total thyroidectomy, through postoperative ${ }^{131} \mathrm{I}$ administration. $2-18 \mathrm{~F}$ fluoro-2-deoxy-d-glucose $\left({ }^{18} \mathrm{~F}\right.$-FDG) is a most common tracer for visualizing glucose metabolism through PET. Cancer imaging via ${ }^{18} \mathrm{~F}$-FDG PET is based on the observation that most cancers, including TC, metabolize glucose at an abnormally high rate [61]. Therefore, evaluation of glucose metabolism through ${ }^{18} \mathrm{~F}$-FDG PET helps differentiate between malignant and benign tumors, staging and diagnosis, treatment, evaluation of therapeutic outcomes, prediction of prognosis, responsiveness assessment, and relapse [62,63]. Moreover, high ${ }^{18}$ F-FDG accumulation is associated with low ${ }^{131} \mathrm{I}$ accumulation based on dedifferentiation of the follicular thyroid cell (flip-flop) [64,65]. However, ${ }^{18}$ F-FDG PET sometimes yields false-positive results, especially in Hashimoto thyroiditis and Graves' disease, and false-negative results for brain metastasis because of their high background levels $[62,66]$.

To resolve these issues, amino acid assessment has gained increasing attention as alternative probes instead of glucose measurement via ${ }^{18} \mathrm{~F}$-FDG. Representative amino acids or their analogs developed as PET probes are L-3- ${ }^{18} \mathrm{~F}$-fluoro- $\alpha$-methyl tyrosine $\left({ }^{18}\right.$ F-FAMT), 6-18F-fluoro-L-3,4-dihydroxy-phenylalanine $\left({ }^{18} \mathrm{~F}\right.$-DOPA), L-[11C-methyl] methionine $\left({ }^{11} \mathrm{C}-\mathrm{MET}\right), \mathrm{O}-(2-$ $[18 \mathrm{~F}]$ fluoroethyl)-l-tyrosine $\left({ }^{18} \mathrm{~F}-\mathrm{FET}\right)$, and ${ }^{18} \mathrm{~F}-\mathrm{NKO}-035 .{ }^{18} \mathrm{~F}$ NKO-035, a LAT1-selective substrate, was recently developed as an anti-cancer agent at Osaka University [67]. A clinical trial revealed that NKO-035 has high affinity for LAT1 (Japanese Registry of Clinical Trials, jRCTs051190057). Of these, ${ }^{18} \mathrm{~F}$ FDOPA and ${ }^{11} \mathrm{C}$-MET have been assessed among TC patients $[68,69] .{ }^{18} \mathrm{~F}-\mathrm{FDOPA}$ PET/CT is a suitable modality for detecting metastatic, persistent, and residual MTC; however, ${ }^{18} \mathrm{~F}-\mathrm{FDG}$ PET/CT may be considered for aggressive MTC in cases displaying signs of dedifferentiation or rapidly rising CEA levels $[68,69]$. Thus far, ${ }^{11} \mathrm{C}-\mathrm{MET}$ PET has not been proven superior to ${ }^{18}$ F-FDG PET in detecting recurrent differentiated TC [70]. However, few studies have focused on amino acid transporters in TC. Further studies are required to determine the utility of amino acid transporter imaging in TC.

\section{Boron neutron capture therapy}

Boron neutron capture therapy (BNCT) is an anticancer therapy using high linear energy transfer alpha particles. Particle radiation is generated by fission reactions when an irradiated thermal neutron beam collides with boron captured by a malignant tumor (Fig. 1). The traveling distance of particle radiation is limited to approximately 5 to $9 \mu \mathrm{m}$, and it then disrupts only cancer cells capturing boron without damaging other cells around target cells $[71,72]$. The success of BNCT depend on ${ }^{10} \mathrm{~B}$ compound concentration of tumor/normal tissue ratios ( $\mathrm{T} / \mathrm{N}$ ratio). This difficult task could be performed by synthesizing a boron compound that is selectively delivered by LAT1. Indeed, p-bo-

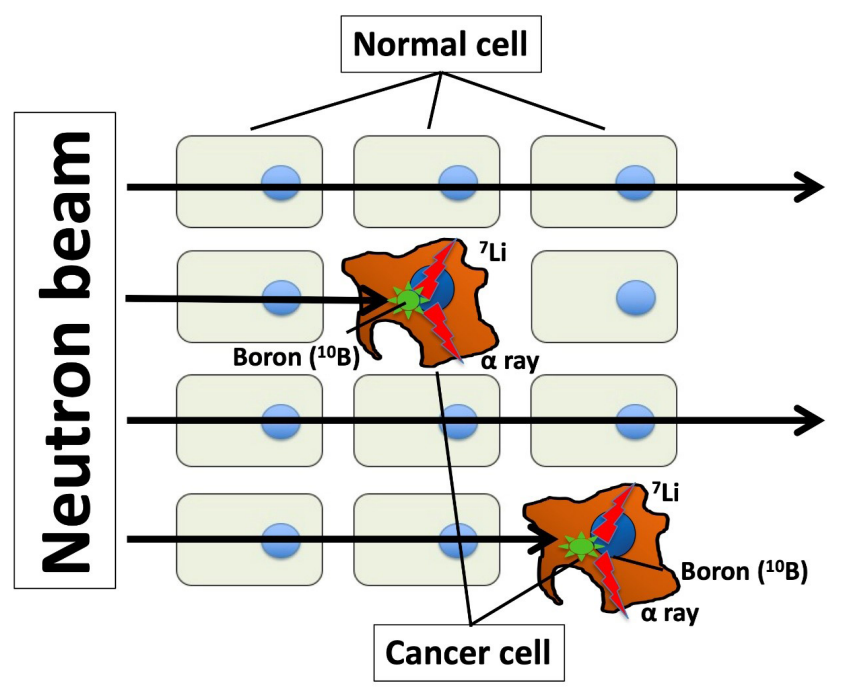

Fig. 1. Schematic representation of the nuclear capture reaction in Boron neutron capture therapy. On irradiation of the ${ }^{10} \mathrm{~B}$ compound, p-boronophenylalanine (BPA), with thermal neutrons, alpha particles and lithium nuclei are obtained, subsequently damaging cancer cells selectively. The track ranges of the two emitted particles within the body are approximately 5 to $9 \mu \mathrm{m}$, and this distance is not greater than the diameter of the cancer cells. The emitted particles thus damage only the cancer cell nuclei and do not approach adjacent normal cells. Therefore, damage is suppressed in normal cells, since they do not take up BPA via L-type amino acid transporter 1 (LAT1), and cancer cells are selectively damaged. 
ronophenylalanine (BPA), a boron compound commonly used in BNCT, is incorporated in cancer cells through LAT1 [73-75], which serves as an optimal mediator for boron delivery. BNCT has achieved certain clinical outcomes in case of high $\mathrm{T} / \mathrm{N}$ ratio in boron concentration; however, it requires a large-scale nuclear reactor to generate neutrons. Nonetheless, a compact accelerator has been developed as an alternative to a nuclear reactor, and it can be installed in a hospital, thus facilitating the easy application of BNCT [76]. Dagrosa et al. [77-79] reported the application of BNCT for undifferentiated TC in vitro and in an in vivo mouse model. However, the clinical advantages of BNCT in TC management remain unknown.

\section{REGULATION OF LAT1}

MYC, a proto-oncogene, is upstream of LAT1. The consensus binding sequence of MYC is located at the LAT1 promoter [80]. Moreover, MYC knockdown downregulates LAT1 in human pancreatic cancer cell lines [80]. MYC is usually expressed at baseline levels in healthy adults [81]; however, MYC overexpression owing to gene amplification, gene translocation, or other gene mutations [82] results in malignant transformation. Notably, MYC is upregulated in patients with TC including ATC, and MYC overexpression promotes TC pathogenesis [8386]. Therefore, MYC is a LAT1 regulator, partly even in TC.

Furthermore, hypoxia-inducible factor (HIF) 2 regulates LAT1. HIF2a, an isoform of the HIF family regulating responses to hypoxia, binds to the LAT1 promoter and upregulates LAT1 in renal carcinoma and neuronal cells $[87,88]$. Exogenous HIF2a upregulation induces LAT1 expression in the lung and liver tissues, wherein LAT1 is generally downregulated [87]. Furthermore, aryl hydrocarbon receptor (AHR) binds to its consensus binding sequence in LAT1 and induces LAT1 expression in breast cancer cell lines [89]. The NOTCH signaling pathway and activating transcription factor 4 (ATF4) also be candidate an important upstream regulator of LAT1 in human T-cell acute lymphoblastic leukemia and prostate cancer, respectively $[33,90]$. The knockdown or small molecule inhibition of EZH2, the epigenetic regulator enhancer of zeste homolog 2, leads to de-repression of RXR $\alpha$ resulting in reduced LAT1 expression in non-small cell lung cancer model [91]. However, the effect of these factors on LAT1 expression in TC is still unclear.

\section{CONCLUSIONS}

Numerous studies have reported the crucial role of amino acids and their transporters in various cancers; however, relatively few studies have determined their potential in the clinical management of TC. A detailed understanding of amino acid metabolism in different cancers would facilitate the development of curative therapy for cancers. Amino acid transporters, especially LAT1, are potential targets for molecular-targeted therapy, imaging, and diagnosis in numerous cancers including TC. The clinical implications of amino acid transporters have recently been reported. Further studies are required to clarify potential molecular targets for treating TC.

\section{CONFLICTS OF INTEREST}

This study was partially supported by Takeda Science Foundation and JSPS KAKENHI Grant Numbers JP20K08939 (PI: Keisuke Enomoto).

\section{ORCID}

Keisuke Enomoto https://orcid.org/0000-0002-6421-5639

Muneki Hotomi https://orcid.org/0000-0003-4705-5319

\section{REFERENCES}

1. Zhu J, Thompson CB. Metabolic regulation of cell growth and proliferation. Nat Rev Mol Cell Biol 2019;20:436-50.

2. Martinez-Outschoorn UE, Peiris-Pages M, Pestell RG, Sotgia F, Lisanti MP. Cancer metabolism: a therapeutic perspective. Nat Rev Clin Oncol 2017;14:11-31.

3. He Y, Gao M, Tang H, Cao Y, Liu S, Tao Y. Metabolic intermediates in tumorigenesis and progression. Int J Biol Sci 2019;15:1187-99.

4. Vettore L, Westbrook RL, Tennant DA. New aspects of amino acid metabolism in cancer. Br J Cancer 2020;122:150-6.

5. Tortolero-Luna G, Torres-Cintron CR, Alvarado-Ortiz M, Ortiz-Ortiz KJ, Zavala-Zegarra DE, Mora-Pinero E. Incidence of thyroid cancer in Puerto Rico and the US by racial/ ethnic group, 2011-2015. BMC Cancer 2019;19:637.

6. Ahn HS, Kim HJ, Kim KH, Lee YS, Han SJ, Kim Y, et al. Thyroid cancer screening in South Korea increases detection of papillary cancers with no impact on other subtypes or thyroid cancer mortality. Thyroid 2016;26:1535-40.

7. Iniguez-Ariza NM, Brito JP. Management of low-risk papillary thyroid cancer. Endocrinol Metab (Seoul) 2018;33:18594.

8. Ito Y, Uruno T, Nakano K, Takamura Y, Miya A, Kobayashi 
$\mathrm{K}$, et al. An observation trial without surgical treatment in patients with papillary microcarcinoma of the thyroid. Thyroid 2003;13:381-7.

9. Ito Y, Miyauchi A, Inoue H, Fukushima M, Kihara M, Higashiyama T, et al. An observational trial for papillary thyroid microcarcinoma in Japanese patients. World J Surg 2010;34:28-35.

10. Sugitani I, Toda K, Yamada K, Yamamoto N, Ikenaga M, Fujimoto Y. Three distinctly different kinds of papillary thyroid microcarcinoma should be recognized: our treatment strategies and outcomes. World J Surg 2010;34:1222-31.

11. Salehian B, Liem SY, Mojazi Amiri H, Maghami E. Clinical trials in management of anaplastic thyroid carcinoma; progressions and set backs: a systematic review. Int J Endocrinol Metab 2019;17:e67759.

12. Sugitani I, Miyauchi A, Sugino K, Okamoto T, Yoshida A, Suzuki S. Prognostic factors and treatment outcomes for anaplastic thyroid carcinoma: ATC Research Consortium of Japan cohort study of 677 patients. World J Surg 2012;36: 1247-54.

13. Hediger MA, Clemencon B, Burrier RE, Bruford EA. The ABCs of membrane transporters in health and disease (SLC series): introduction. Mol Aspects Med 2013;34:95-107.

14. Kanai Y, Segawa H, Miyamoto Ki, Uchino H, Takeda E, Endou H. Expression cloning and characterization of a transporter for large neutral amino acids activated by the heavy chain of 4F2 antigen (CD98). J Biol Chem 1998;273: 23629-32.

15. Mastroberardino L, Spindler B, Pfeiffer R, Skelly PJ, Loffing J, Shoemaker CB, et al. Amino-acid transport by heterodimers of 4F2hc/CD98 and members of a permease family. Nature 1998;395:288-91.

16. Rossier G, Meier C, Bauch C, Summa V, Sordat B, Verrey F, et al. LAT2, a new basolateral 4F2hc/CD98-associated amino acid transporter of kidney and intestine. J Biol Chem 1999;274:34948-54.

17. Segawa H, Fukasawa Y, Miyamoto K, Takeda E, Endou H, Kanai Y. Identification and functional characterization of a $\mathrm{Na}+$-independent neutral amino acid transporter with broad substrate selectivity. J Biol Chem 1999;274:19745-51.

18. Pineda M, Fernandez E, Torrents D, Estevez R, Lopez C, Camps M, et al. Identification of a membrane protein, LAT2, that co-expresses with 4F2 heavy chain, an L-type amino acid transport activity with broad specificity for small and large zwitterionic amino acids. J Biol Chem 1999;274:1973844.
19. Nakada N, Mikami T, Hana K, Ichinoe M, Yanagisawa N, Yoshida T, et al. Unique and selective expression of L-amino acid transporter 1 in human tissue as well as being an aspect of oncofetal protein. Histol Histopathol 2014;29:217-27.

20. Hafliger P, Charles RP. The L-type amino acid transporter LAT1: an emerging target in cancer. Int J Mol Sci 2019;20: 2428.

21. Cormerais Y, Giuliano S, LeFloch R, Front B, Durivault J, Tambutte E, et al. Genetic disruption of the multifunctional CD98/LAT1 complex demonstrates the key role of essential amino acid transport in the control of mTORC1 and tumor growth. Cancer Res 2016;76:4481-92.

22. Furuya M, Horiguchi J, Nakajima H, Kanai Y, Oyama T. Correlation of L-type amino acid transporter 1 and CD98 expression with triple negative breast cancer prognosis. Cancer Sci 2012;103:382-9.

23. Shi L, Luo W, Huang W, Huang S, Huang G. Downregulation of L-type amino acid transporter 1 expression inhibits the growth, migration and invasion of gastric cancer cells. Oncol Lett 2013;6:106-12.

24. Hafliger P, Graff J, Rubin M, Stooss A, Dettmer MS, Altmann KH, et al. The LAT1 inhibitor JPH203 reduces growth of thyroid carcinoma in a fully immunocompetent mouse model. J Exp Clin Cancer Res 2018;37:234.

25. Shen L, Qian C, Cao H, Wang Z, Luo T, Liang C. Upregulation of the solute carrier family 7 genes is indicative of poor prognosis in papillary thyroid carcinoma. World J Surg On$\operatorname{col} 2018 ; 16: 235$.

26. Enomoto K, Sato F, Tamagawa S, Gunduz M, Onoda N, Uchino S, et al. A novel therapeutic approach for anaplastic thyroid cancer through inhibition of LAT1. Sci Rep 2019;9: 14616.

27. Barollo S, Bertazza L, Watutantrige-Fernando S, Censi S, Cavedon E, Galuppini F, et al. Overexpression of L-type amino acid transporter 1 (LAT1) and 2 (LAT2): novel markers of neuroendocrine tumors. PLoS One 2016;11:e0156044.

28. Braun D, Wirth EK, Wohlgemuth F, Reix N, Klein MO, Gruters A, et al. Aminoaciduria, but normal thyroid hormone levels and signalling, in mice lacking the amino acid and thyroid hormone transporter Slc7a8. Biochem J 2011; 439:249-55.

29. Verrey F, Closs EI, Wagner CA, Palacin M, Endou H, Kanai Y. CATs and HATs: the SLC7 family of amino acid transporters. Pflugers Arch 2004;447:532-42.

30. Badziong J, Ting S, Synoracki S, Tiedje V, Brix K, Brabant $\mathrm{G}$, et al. Differential regulation of monocarboxylate trans- 
porter 8 expression in thyroid cancer and hyperthyroidism. Eur J Endocrinol 2017;177:243-50.

31. Babu E, Kanai Y, Chairoungdua A, Kim DK, Iribe Y, Tangtrongsup $\mathrm{S}$, et al. Identification of a novel system $\mathrm{L}$ amino acid transporter structurally distinct from heterodimeric amino acid transporters. J Biol Chem 2003;278:43838-45.

32. Cole KA, Chuaqui RF, Katz K, Pack S, Zhuang Z, Cole CE, et al. cDNA sequencing and analysis of POV1 (PB39): a novel gene up-regulated in prostate cancer. Genomics 1998; 51:282-7.

33. Wang Q, Bailey CG, Ng C, Tiffen J, Thoeng A, Minhas V, et al. Androgen receptor and nutrient signaling pathways coordinate the demand for increased amino acid transport during prostate cancer progression. Cancer Res 2011;71:7525-36.

34. Bodoy S, Martin L, Zorzano A, Palacin M, Estevez R, Bertran J. Identification of LAT4, a novel amino acid transporter with system L activity. J Biol Chem 2005;280:12002-11.

35. Fuchs BC, Finger RE, Onan MC, Bode BP. ASCT2 silencing regulates mammalian target-of-rapamycin growth and survival signaling in human hepatoma cells. Am J Physiol Cell Physiol 2007;293:C55-63.

36. Kanai Y, Hediger MA. The glutamate and neutral amino acid transporter family: physiological and pharmacological implications. Eur J Pharmacol 2003;479:237-47.

37. Zhang Z, Liu R, Shuai Y, Huang Y, Jin R, Wang X, et al. ASCT2 (SLC1A5)-dependent glutamine uptake is involved in the progression of head and neck squamous cell carcinoma. Br J Cancer 2020;122:82-93.

38. Liu Y, Zhao T, Li Z, Wang L, Yuan S, Sun L. The role of ASCT2 in cancer: a review. Eur J Pharmacol 2018;837:81-7.

39. Kim HM, Lee YK, Koo JS. Expression of glutamine metabolism-related proteins in thyroid cancer. Oncotarget 2016;7: 53628-41.

40. Pramod AB, Foster J, Carvelli L, Henry LK. SLC6 transporters: structure, function, regulation, disease association and therapeutics. Mol Aspects Med 2013;34:197-219.

41. Coothankandaswamy V, Cao S, Xu Y, Prasad PD, Singh PK, Reynolds CP, et al. Amino acid transporter SLC6A14 is a novel and effective drug target for pancreatic cancer. Br J Pharmacol 2016;173:3292-306.

42. Polewski MD, Reveron-Thornton RF, Cherryholmes GA, Marinov GK, Aboody KS. SLC7A11 overexpression in glioblastoma is associated with increased cancer stem celllike properties. Stem Cells Dev 2017;26:1236-46.

43. Takeuchi S, Wada K, Toyooka T, Shinomiya N, Shimazaki $\mathrm{H}$, Nakanishi K, et al. Increased xCT expression correlates with tumor invasion and outcome in patients with glioblastomas. Neurosurgery 2013;72:33-41.

44. Vekony N, Wolf S, Boissel JP, Gnauert K, Closs EI. Human cationic amino acid transporter hCAT-3 is preferentially expressed in peripheral tissues. Biochemistry 2001;40:12387-94.

45. El Ansari R, Craze ML, Miligy I, Diez-Rodriguez M, Nolan CC, Ellis IO, et al. The amino acid transporter SLC7A5 confers a poor prognosis in the highly proliferative breast cancer subtypes and is a key therapeutic target in luminal B tumours. Breast Cancer Res 2018;20:21.

46. Bik-Multanowski M, Pietrzyk JJ. LAT1 gene variants: potential factors influencing the clinical course of phenylketonuria. J Inherit Metab Dis 2006;29:684.

47. Espino Guarch M, Font-Llitjos M, Murillo-Cuesta S, ErrastiMurugarren E, Celaya AM, Girotto G, et al. Mutations in Ltype amino acid transporter-2 support SLC7A8 as a novel gene involved in age-related hearing loss. Elife 2018;7: e31511.

48. Ito T, Seyama T, Hayashi Y, Hayashi T, Dohi K, Mizuno T, et al. Establishment of 2 human thyroid-carcinoma cell-lines $(8305 \mathrm{c}, 8505 \mathrm{c})$ bearing p53 gene-mutations. Int J Oncol 1994;4:583-6.

49. Zhang L, Zhang Y, Mehta A, Boufraqech M, Davis S, Wang J, et al. Dual inhibition of HDAC and EGFR signaling with CUDC-101 induces potent suppression of tumor growth and metastasis in anaplastic thyroid cancer. Oncotarget 2015;6: 9073-85.

50. Kaira K, Oriuchi N, Imai H, Shimizu K, Yanagitani N, Sunaga N, et al. Prognostic significance of L-type amino acid transporter 1 expression in resectable stage I-III nonsmall cell lung cancer. Br J Cancer 2008;98:742-8.

51. Ichinoe M, Yanagisawa N, Mikami T, Hana K, Nakada N, Endou H, et al. L-type amino acid transporter 1 (LAT1) expression in lymph node metastasis of gastric carcinoma: its correlation with size of metastatic lesion and Ki-67 labeling. Pathol Res Pract 2015;211:533-8.

52. Kaira K, Oriuchi N, Imai H, Shimizu K, Yanagitani N, Sunaga $\mathrm{N}$, et al. Expression of L-type amino acid transporter 1 (LAT1) in neuroendocrine tumors of the lung. Pathol Res Pract 2008;204:553-61.

53. Janpipatkul K, Suksen K, Borwornpinyo S, Jearawiriyapaisarn N, Hongeng S, Piyachaturawat $\mathrm{P}$, et al. Downregulation of LAT1 expression suppresses cholangiocarcinoma cell invasion and migration. Cell Signal 2014;26:1668-79.

54. Kaji M, Kabir-Salmani M, Anzai N, Jin CJ, Akimoto Y, Horita A, et al. Properties of L-type amino acid transporter 1 
in epidermal ovarian cancer. Int J Gynecol Cancer 2010;20: 329-36.

55. McClellan WM, Schafer JA. Transport of the amino acid analog, 2-aminobicyclo(2,2,1)-heptane-2-carboxylic acid, by Ehrlich ascites tumor cells. Biochim Biophys Acta 1973; 311:462-75.

56. Kim CS, Cho SH, Chun HS, Lee SY, Endou H, Kanai Y, et al. $\mathrm{BCH}$, an inhibitor of system $\mathrm{L}$ amino acid transporters, induces apoptosis in cancer cells. Biol Pharm Bull 2008;31: 1096-100.

57. Oda K, Hosoda N, Endo H, Saito K, Tsujihara K, Yamamura $\mathrm{M}$, et al. L-type amino acid transporter 1 inhibitors inhibit tumor cell growth. Cancer Sci 2010;101:173-9.

58. Kongpracha P, Nagamori S, Wiriyasermkul P, Tanaka Y, Kaneda K, Okuda S, et al. Structure-activity relationship of a novel series of inhibitors for cancer type transporter L-type amino acid transporter 1 (LAT1). J Pharmacol Sci 2017;133: 96-102.

59. Okano N, Naruge D, Kawai K, Kobayashi T, Nagashima F, Endou H, et al. First-in-human phase I study of JPH203, an L-type amino acid transporter 1 inhibitor, in patients with advanced solid tumors. Invest New Drugs 2020 Mar 20 [Epub]. https://doi.org/10.1007/s10637-020-00924-3.

60. Al Moudi M, Sun Z, Lenzo N. Diagnostic value of SPECT, $\mathrm{PET}$ and PET/CT in the diagnosis of coronary artery disease: a systematic review. Biomed Imaging Interv J 2011;7:e9.

61. Gatenby RA, Gillies RJ. Why do cancers have high aerobic glycolysis? Nat Rev Cancer 2004;4:891-9.

62. Khan N, Oriuchi N, Higuchi T, Zhang H, Endo K. PET in the follow-up of differentiated thyroid cancer. Br J Radiol 2003;76:690-5.

63. Kim H, Na KJ, Choi JH, Ahn BC, Ahn D, Sohn JH. Feasibility of FDG-PET/CT for the initial diagnosis of papillary thyroid cancer. Eur Arch Otorhinolaryngol 2016;273:1569-76.

64. Feine U, Lietzenmayer R, Hanke JP, Wohrle H, MullerSchauenburg W. 18FDG whole-body PET in differentiated thyroid carcinoma: flipflop in uptake patterns of $18 \mathrm{FDG}$ and 131I. Nuklearmedizin 1995;34:127-34.

65. Feine U, Lietzenmayer R, Hanke JP, Held J, Wohrle H, Muller-Schauenburg W. Fluorine-18-FDG and iodine131-iodide uptake in thyroid cancer. J Nucl Med 1996;37: 1468-72.

66. Chen W, Parsons M, Torigian DA, Zhuang H, Alavi A. Evaluation of thyroid FDG uptake incidentally identified on FDG-PET/CT imaging. Nucl Med Commun 2009;30:240-4. 67. Katayama D, Watabe T, Nagamori S, Kanai Y, Naka S, Liu Y, et al. Preclinical evaluation of new PET tracer targeting Ltype amino acid transporter 1 (LAT1): F-18 NKO-035 PET in inflammation model of rats. J Nucl Med 2018;59(Suppl 1):1121.

68. Beheshti M, Pocher S, Vali R, Waldenberger P, Broinger G, Nader M, et al. The value of 18F-DOPA PET-CT in patients with medullary thyroid carcinoma: comparison with $18 \mathrm{~F}$ FDG PET-CT. Eur Radiol 2009;19:1425-34.

69. Giovanella L, Treglia G, Iakovou I, Mihailovic J, Verburg FA, Luster M. EANM practice guideline for PET/CT imaging in medullary thyroid carcinoma. Eur J Nucl Med Mol Imaging 2020;47:61-77.

70. Phan HT, Jager PL, Plukker JT, Wolffenbuttel BH, Dierckx RA, Links TP. Comparison of 11C-methionine PET and 18F-fluorodeoxyglucose PET in differentiated thyroid cancer. Nucl Med Commun 2008;29:711-6.

71. Barth RF, Coderre JA, Vicente MG, Blue TE. Boron neutron capture therapy of cancer: current status and future prospects. Clin Cancer Res 2005;11:3987-4002.

72. Das BC, Thapa P, Karki R, Schinke C, Das S, Kambhampati $\mathrm{S}$, et al. Boron chemicals in diagnosis and therapeutics. Future Med Chem 2013;5:653-76.

73. Detta A, Cruickshank GS. L-amino acid transporter-1 and boronophenylalanine-based boron neutron capture therapy of human brain tumors. Cancer Res 2009;69:2126-32.

74. Wongthai P, Hagiwara K, Miyoshi Y, Wiriyasermkul P, Wei L, Ohgaki R, et al. Boronophenylalanine, a boron delivery agent for boron neutron capture therapy, is transported by ATB0,+, LAT1 and LAT2. Cancer Sci 2015;106:279-86.

75. Watabe T, Ikeda H, Nagamori S, Wiriyasermkul P, Tanaka Y, Naka S, et al. 18F-FBPA as a tumor-specific probe of L-type amino acid transporter 1 (LAT1): a comparison study with 18F-FDG and 11C-Methionine PET. Eur J Nucl Med Mol Imaging 2017;44:321-31.

76. Sauerwein W, Wittig A, Moss R, Nakagawa Y. Neutron capture therapy. Berlin: Springer; 2012. Chapter 4, Compact Neutron Generator for BNCT; p. 55-68.

77. Dagrosa MA, Viaggi M, Kreimann E, Farias S, Garavaglia $\mathrm{R}$, Agote M, et al. Selective uptake of p-borophenylalanine by undifferentiated thyroid carcinoma for boron neutron capture therapy. Thyroid 2002;12:7-12.

78. Dagrosa MA, Viaggi M, Longhino J, Calzetta O, Cabrini R, Edreira M, et al. Experimental application of boron neutron capture therapy to undifferentiated thyroid carcinoma. Int J Radiat Oncol Biol Phys 2003;57:1084-92.

79. Dagrosa MA, Thomasz L, Longhino J, Perona M, Calzetta 
$\mathrm{O}$, Blaumann H, et al. Optimization of boron neutron capture therapy for the treatment of undifferentiated thyroid cancer. Int J Radiat Oncol Biol Phys 2007;69:1059-66.

80. Hayashi K, Jutabha P, Endou H, Anzai N. c-Myc is crucial for the expression of LAT1 in MIA Paca-2 human pancreatic cancer cells. Oncol Rep 2012;28:862-6.

81. Wierstra I, Alves J. The c-myc promoter: still MysterY and challenge. Adv Cancer Res 2008;99:113-333.

82. Vita M, Henriksson M. The Myc oncoprotein as a therapeutic target for human cancer. Semin Cancer Biol 2006;16:31830.

83. Bieche I, Franc B, Vidaud D, Vidaud M, Lidereau R. Analyses of MYC, ERBB2, and CCND1 genes in benign and malignant thyroid follicular cell tumors by real-time polymerase chain reaction. Thyroid 2001;11:147-52.

84. Sakr HI, Chute DJ, Nasr C, Sturgis CD. cMYC expression in thyroid follicular cell-derived carcinomas: a role in thyroid tumorigenesis. Diagn Pathol 2017;12:71.

85. Zhu X, Enomoto K, Zhao L, Zhu YJ, Willingham MC, Meltzer P, et al. Bromodomain and extraterminal protein inhibitor JQ1 suppresses thyroid tumor growth in a mouse model. Clin Cancer Res 2017;23:430-40.

86. Enomoto K, Zhu X, Park S, Zhao L, Zhu YJ, Willingham $\mathrm{MC}$, et al. Targeting MYC as a therapeutic intervention for anaplastic thyroid cancer. J Clin Endocrinol Metab 2017; 102:2268-80.

87. Elorza A, Soro-Arnaiz I, Melendez-Rodriguez F, RodriguezVaello V, Marsboom G, de Carcer G, et al. HIF2 $\alpha$ acts as an mTORC1 activator through the amino acid carrier SLC7A5. Mol Cell 2012;48:681-91.

88. Onishi Y, Hiraiwa M, Kamada H, Iezaki T, Yamada T, Kaneda K, et al. Hypoxia affects Slc7a5 expression through HIF- $2 \alpha$ in differentiated neuronal cells. FEBS Open Bio 2019;9:241-7.

89. Tomblin JK, Arthur S, Primerano DA, Chaudhry AR, Fan J, Denvir J, et al. Aryl hydrocarbon receptor (AHR) regulation of L-type amino acid transporter 1 (LAT-1) expression in MCF-7 and MDA-MB-231 breast cancer cells. Biochem Pharmacol 2016;106:94-103.

90. Grzes KM, Swamy M, Hukelmann JL, Emslie E, Sinclair LV, Cantrell DA. Control of amino acid transport coordinates metabolic reprogramming in T-cell malignancy. Leukemia 2017;31:2771-9.

91. Dann SG, Ryskin M, Barsotti AM, Golas J, Shi C, Miranda $\mathrm{M}$, et al. Reciprocal regulation of amino acid import and epigenetic state through Lat1 and EZH2. EMBO J 2015;34: 1773-85. 